\title{
Epilepsy and tropical parasitic infections in Sub-Saharan Africa: a review
}

\author{
HUMPHREY D. MAZIGO ${ }^{1 *}$, DOMENICA MORONA ${ }^{1}$, ELININGAYA J. KWEKA ${ }^{12}$, REBECCA WAIHENYA $^{3}$, LADSLAUS \\ L. MNYONE ${ }^{4}$ and J ORG HEUKELBACH ${ }^{5}$ \\ DDepartment of Medical Parasitology and Entomology, School of Medicine, Catholic University of Health and Allied \\ Sciences, P.O. Box 1464, Mwanza, Tanzania \\ ${ }^{2}$ Tropical Pesticides Research Institute, P.O. Box 3024, Arusha, Tanzania \\ ${ }^{3}$ Faculty of Science, J omo Kenyatta University of Agriculture and Technology, Nairobi, Kenya \\ ${ }^{4}$ Biomedical and Environmental Thematic Group, Ifakara Health Institute, P.O. Box 53, Ifakara, Tanzania \\ ${ }^{5}$ Department of Community Health, School of Medicine, Federal University of Ceará, Brazil
}

\begin{abstract}
Several reports have suggested that the high prevalence of epilepsy in sub-Saharan Africa is associated with the high prevalence of parasitic infections affecting the central nervous system. Though epidemiological evidence suggests an association between parasitic infections and epilepsy, the biological causal relationship has not been fully demonstrated for many of these infections. The objective of this paper is to review the available epidemiological evidence on the links between parasitic infections and epilepsy, the pathogenesis and the current gap of knowledge indicating the areas requiring further research. Data for this review were identified and collected using manual and electronic search strategies of published and unpublished sources. In Sub-Saharan Africa, the epidemiology of epilepsy remains unclear and given the differing study designs, the results of available epidemiological studies are difficult to interpret and compare. Evidence from surveys reported a median prevalence of $15 \%$ Co-infection of parasitic infections and epilepsy in sub-Saharan Africa are common, particularly in areas characterized by poor hygiene standards. There is an epidemiological link on the association between epilepsy and various parasitic infections. However, the biological causal relationship requires further investigation in adequately designed studies. In conclusion, although several epidemiological and case control studies indicate a relationship between parasitic agents and epilepsy in sub-Saharan Africa, there is a considerable gap of knowledge on the cause and magnitude of the association. Thus, there is an urgent need for systematic epidemiological studies to understand the burden of epilepsy in areas endemic due to preventable parasitic infections, to prove a causal relationship, and to understand the impact of controlling these parasitic diseases on reduction of the burden of epilepsy.
\end{abstract}

Keywords: parasitic infections, epilepsy, epidemiology and pathogenesis, Sub-Saharan Africa

\section{Introduction}

Epilepsy is a neurological disorder characterized by recurrent unprovoked epileptic seizures due to unknown or immediate known aetiology (Hauser $\&$ Kurland., 1975; Fisher et al., 2005). Two types of epilepsy are known: the primary or idiopathic epilepsy with its aetiology mainly unknown, and the secondary or symptomatic epilepsy which originates from cerebral lesions that may, be traumatic, hypoxic or infectious in origin amongst others (Hauser \& Kurland., 1975; Fisher et al., 2005). Epilepsy is responsible for high levels of suffering, affecting more than 50 million people worldwide (WHO, 2001a,b; Forsgren et al., 2005; Forsgren, 2008), with 40 million living in tropical areas, where the disease affects all age groups (WHO, 2001a,b). Another estimate by WHO indicates that 8.5 per 1000 persons worldwide have epilepsy (Forsgren et al., 2005; Forsgren, 2008) and that the prevalence of the disease is not evenly distributed, with considerably higher prevalence in resource-poor than resource-rich countries (CTILAE, 1994; Stommel et al., 2001; Burneo et al., 2005; Preux \& DruetCabanac, 2005; Wagner \& Newton., 2009).

In high income countries, traumatic head/brain injuries and stroke are the main causes of epilepsy (Epilepsy and Driving in Europe., 2005; Forsgren et al., 2005; Garcia-Martin et al., 2012; Rai et

\footnotetext{
*Correspondence: humphreymazigo@gmail.com/humphreymazigo@bugando.ac.tz
} 
al., 2012) whereas in low and middle income countries, central nervous system infections due to viral, bacterial and parasitic infections seem to contribute to the high prevalence of epilepsy (WHO, 2001a; Forsgren, 2008). The Commission on Tropical Diseases of the International League Against Epilepsy has identified several tropical diseases as possible aetiological agents of epilepsy (WHO, 2001a), with parasitic infections as a major cause (WHO, 2001a). In the tropics, especially in sub-Saharan Africa, there is high endemicity for several parasitic infections, which at some stage of their pathogenesis may invade the central nervous system (CNS) and cause neurological conditions such as epilepsy (Stommel et al., 2001). Parasites may cause epileptic seizures or long-term epilepsy by producing either diffuse encephalitis or localised lesions (De Bittencourt et al., 1988; Adamolekun., 1995; Neto \& De Bittencout, 1996; De Bittencout et al., 1996).

In the present review, we give an epidemiological overview of common parasitic infections associated with epileptic seizures and epilepsy, their geographic distribution and the possible mechanisms through which these parasitic infections can cause seizures and epilepsy.

\section{Methodology}

Data for this review were identified and collected using manual and electronic search strategies of published and unpublished sources. Electronic databases included PubMed, EMBASE, WHO and Global Health. References of relevant articles were also screened. To identify relevant studies on epilepsy and various parasitic infections, various combinations of the following terms were used: "central nervous system infections", "parasitic infections", "helminth infections", "protozoan infections", "neurocysticercosis", "toxocariasis", "onchorcerciasis", "schistosomiasis", "paragonimus", "epilepsy", "unprovoked seizure" etc. In a specific search, for example in the case of infections like schistosomiasis, an advanced search in PubM ed was employed.

\section{Epidemiology of epilepsy and parasitic infections in sub-Saharan Africa}

In Sub-Saharan Africa, the epidemiology of epilepsy remains unclear and given the differing study designs, the results of available epidemiological studies are difficult to interpret and compare (Sander \& Shorvon, 1987). Several studies of epilepsy prevalence have been conducted in subSaharan Africa and the prevalence estimates from these studies vary widely between and within countries (Preux \& Druet-Cabanac, 2005). Evidence from door-to-door surveys reported a median prevalence of $15 \%$ (Preux \& Druet-Cabanac, 2005). In West Africa, specifically in Benin, the prevalence of epilepsy in rural villages was estimated to be $16 \%$ (Hook $\&$ Regal, 1995) and a door to door survey in the same country have reported that crude prevalence of epilepsy in the 15 years and older individuals in Benin to be 8.05 per 1000 while the crude prevalence of epilepsy among men was 9.77 per 1000 and 6.79 per 1000 for women (Yamadje et al., 2012). The recent report from Benin indicates that, the prevalence of epilepsy is 10.5 per 1000 (Houinato et al., 2013). In rural Burkina Faso, the prevalence of epilepsy was estimated to be $4.5 \%$ (Nitiema et al., 2012). In Ulanga district in rural eastern Tanzania, the prevalence of epilepsy was 10.2 per 1000 (range $=5.1-37.1$ per 1000) individuals and varied between villages (Rwiza et al., 1992). In northern Tanzania, the prevalence rate of epilepsy was reported to be 112 per 1000 and the age-adjusted prevalence rate was 13.2 per 1000 (Winkler et al., 2009). The prevalence of active epilepsy was 8.7 per 1000 and there was a preponderance of women (Winkler et al., 2009). In the southern part of Tanzania, the prevalence of active epilepsy was reported to be 8.6 per 1000 (Dent et al., 2005).

In general, the prevalence of epilepsy in Africa is estimated to range between $0.05 \%$ and $7.4 \%$ (Preux \& Druet-Cabanac., 2005), depending on the type of study and methodology used, amongst others. There are regional differences on prevalence of epilepsy, between countries and regions 
within a country. For instance, in rural southern, eastern and northern Tanzania, the population based surveys have reported a variation in prevalence ranging from 8.6 to 112 per 1000 (Rwiza et al., 1992; Dent et al., 2005; Winkler et al., 2009). Similarly, two studies in Nigeria observed a variation of epilepsy prevalence in the same ethnic community (Adeuja et al., 1982; Longe \& Osuntokun., 1989). The variation in prevalence could in part be explained by genetic influences, variation in sanitary conditions, parasitic infections, prevention of birth, area of residential between rural and urban, diagnosis difficulties and head injuries among others (Nkwi \& Ndonko., 1989; Preux \& Druet-Cabanac, 2005).

Studies on the incidence of epilepsy in rural areas of Africa have reported an annual incidence rate of 63-158 new cases per 100,000 population, approximately four times higher than what has been reported from high income countries in non-tropical areas (Preux \& Druet-Cabanac, 2005). Incidence in Uganda is higher than that reported in Ethiopia ( 215 new cases per 100,000 population versus 64 new cases per 100,000 populations versus) Tekle-Haimanot, 1997; Kaiser et al., 1998; Winkler et al., 2009).

The risk factors for epilepsy in sub-Saharan Africa vary widely and seem to depend on the level of demographic and socio-economic status (Senanayake \& Roman, 1993; Preux \& DruetCabanac, 2005). Most of the studies appear to underestimate the prevalence due to the lack of clinical tests and most of the causal information is derived from the patient's history (Adamolekun, 1995; WHO, 2001a). The identified risk factors include parasitic, viral and bacterial infections of the central nervous system, perinatal complications, head injuries, brain tumours, cerebrovascular diseases and residential area (rural versus urban areas) (Adeloye, 1976; Senanayake \& Roman, 1993; CTDILAE, 1994; Ogunniyi et al., 1994; Adamolekun, 1995; De Bittencourt et al., 1998; Preux \& DruetCabanac, 2005; Wagner \& Newton, 2009). In addition, a family history of epilepsy seems to enhance the risk of epilepsy (Bitterncoourt et al., 1999). For epilepsy resulting from parasitic infections, the interaction between parasitic agents, social economic status, genetics and environmental factors determines the magnitude of developing epilepsy (Johnson \& Sander, 2001). In general, in subSaharan Africa, the aetiology of epilepsy is multifactorial and may include different agents such as helminths and protozoans.

Helminths infections either due to nematodes, trematodes or cestodes, are highly endemic in sub-Saharan Africa (Hotez et al., 2008; Hotez \& Kamath, 2009). Worldwide, estimates indicate that 2.2 billion individuals are infected with at least one species of helminths (Hotez \& Kamath, 2009). In sub-Saharan Africa, an estimated 813 million people are infected with helminths (Hotez \& Kamath, 2009). Most people infected remain asymptomatic. In symptomatic individuals, helminth infections are associated with blood loss, anaemia, poor grow th and reduced cognitive functions (Hotez et al., 2008). In chronic stages, helminth infections are associated with severe morbidities such as cancer of the urinary bladder, urogenital complications, and liver fibrosis (Hotez et al., 2008; Andrade, 2009). A number of helminth species can infect the central nervous system (Walker \& Zunt, 2005; Garzia \& Modi, 2008;Wagner \& Newton, 2009) and cause epileptic seizures, but only a few are associated with epilepsy (Walker \& Zunt, 2005; Garzia \& Modi, 2008; Wagner \& Newton, 2009). Table 1 shows helminth species endemic in sub-Saharan Africa, which may infect the brain and cause epileptic seizures or epilepsy (Walker \& Zunt, 2005; Garzia \& M odi, 2008; Wagner \& Newton, 2009). 
Table 1: Helminth infections infecting the central nervous system, associated with epilepsy in subSaharan Africa

\begin{tabular}{|c|c|c|c|c|c|}
\hline $\begin{array}{l}\text { Group } \\
\text { parasites }\end{array}$ & of & Parasitic agent & Definitive hosts & $\begin{array}{l}\text { Intermediate } \\
\text { hosts }\end{array}$ & $\begin{array}{l}\text { Disease (s) or neurological } \\
\text { complications }\end{array}$ \\
\hline \multirow{3}{*}{\multicolumn{2}{|c|}{ Cestodes }} & Taenia solium & Human & Pigs & Neurocysticercosis and \\
\hline & & & & & $\begin{array}{l}\text { other signs such as } \\
\text { epilepsy }\end{array}$ \\
\hline & & $\begin{array}{l}\text { Echinococcus } \\
\text { granulosus }\end{array}$ & $\begin{array}{l}\text { Dogs and other } \\
\text { wild canines }\end{array}$ & $\begin{array}{l}\text { Domesticated } \\
\text { and wild } \\
\text { herbivores }\end{array}$ & $\begin{array}{l}\text { Neuroechinococcosis, } \\
\text { seizures and epilepsy }\end{array}$ \\
\hline \multirow{3}{*}{\multicolumn{2}{|c|}{ Nematodes }} & $\begin{array}{l}\text { Onchocerca } \\
\text { volvulus }\end{array}$ & Human & $\begin{array}{l}\text { Black flies } \\
\text { (Simulium } \\
\text { species) }\end{array}$ & $\begin{array}{l}\text { Dermatitis, } \\
\text { neuroonchocerciasis, } \\
\text { seizure and epilepsy }\end{array}$ \\
\hline & & Trichinella spiralis & Humans & $\begin{array}{l}\text { Domesticated } \\
\text { and wild pigs }\end{array}$ & $\begin{array}{l}\text { Neurotrichinosis, seizure } \\
\text { and epilepsy }\end{array}$ \\
\hline & & Toxocara canis & Dogs, cats & No & $\begin{array}{l}\text { Seizure, epilepsy and } \\
\text { neurotoxocariasis }\end{array}$ \\
\hline \multirow{3}{*}{\multicolumn{2}{|c|}{ Trematodes }} & $\begin{array}{l}\text { Schisto somiasis } \\
\text { (S. mansoni and S. } \\
\text { haematobium) }\end{array}$ & Human & $\begin{array}{l}\text { Fresh water } \\
\text { Snails } \\
\text { (Biomphalaria }\end{array}$ & $\begin{array}{l}\text { Neuroschistosomiasis, } \\
\text { seizure and epilepsy }\end{array}$ \\
\hline & & & & $\begin{array}{ll}\text { and } & \text { Bulinus } \\
\text { species) } & \end{array}$ & \\
\hline & & $\begin{array}{l}\text { Paragonimus } \\
\text { species }\end{array}$ & $\begin{array}{l}\text { Human } \\
\text { other } \\
\text { animals }\end{array}$ & $\begin{array}{l}\text { Snails, } \\
\text { crustaceans }\end{array}$ & $\begin{array}{l}\text { Neuroparagonimiasis, } \\
\text { seizure and epilepsy }\end{array}$ \\
\hline
\end{tabular}

Plasmodium falciparum malaria is still widely distributed and highly endemic in the region (WHO, 2011). An estimated 3.3 billion people were at risk of malaria in 2010, although of all geographical regions, populations living in sub-Saharan Africa have the highest risk of acquiring malaria; in 2010, $81 \%$ of cases and $91 \%$ of deaths were estimated to have occurred in sub-Saharan Africa, with children under five years of age and pregnant women being most severely affected (WHO, 2011) The epidemiology of amoebiasis and toxoplasmosis in sub-Saharan Africa is poorly understood (Stauffer, 2005). Blood and intestinal protozoan parasites such as P. falciparum, Toxoplasma gondii and Amoeba species (Entamoeba histolytica) are highly endemic in sub- Saharan Africa (Okeke et al., 2003). Based on the similarities on the level of environmental hygiene in African communities and evidence from Seroprevalence studies, it appears that amoebiasis is widely distributed and in some countries may be associated with liver morbidities (Okeke et al., 2003).

\section{Tropical parasitic infections associated with epilepsy in sub-Saharan Africa}

Information on other environmental amoeba species such as Naegleria fowlerii and Acanthamoeba is very limited in sub-Saharan Africa. Similarly, most of the seroprevalence studies on toxoplasmosis in the area have been undertaken among special groups such as pregnant women, children and HIV/AIDS patients (Onadeko et al., 1992; Falusi et al., 2002; Alnahas et al., 2003; Uneke et al., 2005; Amogne et al., 2006; Swai \& Schoonman, 2009). Available evidence indicates that blood and intestinal protozoan parasites are associated with epilepsy and will be discussed hereafter. Table 2 shows some protozoan parasites which can infect the brain and cause seizures or epilepsy. 
Table 2: Protozoan infections associated with epilepsy in sub-Saharan Africa

\begin{tabular}{|c|c|c|c|c|}
\hline $\begin{array}{l}\text { Group } \\
\text { parasites }\end{array}$ & Parasitic agent & Definitive hosts & $\begin{array}{l}\text { Intermediate } \\
\text { hosts }\end{array}$ & $\begin{array}{l}\text { Disease (s) or } \\
\text { neurological } \\
\text { complications }\end{array}$ \\
\hline \multirow[t]{2}{*}{ Blood protozoans } & $\begin{array}{l}\text { Plasmodium } \\
\text { falciparum }\end{array}$ & Anopheles species & Human & $\begin{array}{l}\text { Cerebral malaria, seizure } \\
\text { and epilepsy }\end{array}$ \\
\hline & Toxoplasma gondii & $\begin{array}{l}\text { Cats and other } \\
\text { felines }\end{array}$ & $\begin{array}{l}\text { Human and other } \\
\text { mammals }\end{array}$ & $\begin{array}{l}\text { Congenital disease, } \\
\text { meningoencephalitis, } \\
\text { neurotoxoplasmosis }\end{array}$ \\
\hline Intestinal Amoeba & $\begin{array}{l}\text { Entamoeba } \\
\text { histolytica }\end{array}$ & Human & No & Cerebral amoebiasis \\
\hline \multirow[t]{2}{*}{$\begin{array}{l}\text { Environmental } \\
\text { amoebiasis }\end{array}$} & Neigleria fow leri & NA & NA & $\begin{array}{l}\text { Primary amoebic } \\
\text { meningoencephalitis and } \\
\text { other neuro related } \\
\text { complications }\end{array}$ \\
\hline & $\begin{array}{l}\text { Acanthamoeba } \\
\text { histolytica }\end{array}$ & NA & NA & $\begin{array}{l}\text { Granulomatous amoebic } \\
\text { encephalitis }\end{array}$ \\
\hline
\end{tabular}

\section{Cestodes}

Taenia solium and neurocysticercosis: Cysticercosis is the infection with larval or metacestode stages (cysticerca) of Taenia solium. Human beings are the definitive hosts and harbour the adult tapeworm. Transmission of infection to humans occurs through ingestion of the larval stage in undercooked pork for human being, and pigs are infected through scavenging of human excreta on the environment (Carpio, 2002). In addition, human beings are infected through internal and external autoinfection (Faust et al., 1979; Pawloski et al., 2002; Carpio., 2002). Also, there is heteroinfection in which the T. solium eggs may be ingested in contaminated food or drinking water (Carpio, 2002). The eggs are digested in the stomach and the larval stages, oncosphere are released and penetrate the intestinal muscles and reach the various body tissues and the brain via blood (Preux et al., 1996).

Taenia solium and taeniasis are highly endemic in sub-Saharan Africa and commonly seen in areas were pork is consumed (Pawloski et al., 2002; Carpio, 2002; Winkler et al., 2009; Winkler, 2012). The disease is mainly associated with poor socioeconomic status and socio-cultural factors (Gemmell \& J ohnstone, 1976; Carpio et al., 2002; Pawloski et al., 2002). Poor hygiene and living conditions and a free range system of keeping pigs which allows them to scavenge on human faeces increase the risk of human cysticercosis (Gemmell \& J ohnstone, 1976; Carpio et al., 2002: Pawloski et al., 2002).

Taenia solium which cause neurocysticercosis seems to be an important cause of epilepsy in the tropics (Gemmell \& J ohnstone, 1976; Carpio et al., 2002: Pawloski et al., 2002; Winkler et al., 2009; Winkler, 2012). Neurocysticercosis is a commonest parasitic CNS disease which results from an infection of the larval form of T. solium in the central nervous system (Pal et al., 2000). The cysts are mainly seen in the parenchyma of the brain, brain ventricles, meninges, spinal cord, eye and subarachnoid space (Pal et al., 2000). Evidence suggests that the compression of brain tissues and an early inflammatory response characterized by diffuse encephalitis or localized inflammatory lesions are responsible for seizures or for long term epilepsy (Gemmell \& J ohnstone, 1976; Pawloski, 2002; Wagner \& Newton, 2009; Nash \& Garcia, 2011). Epidemiological studies from sub-Saharan Africa have shown the association of neurocysticercosis with seizures or epilepsy (Gemmell \& J ohnstone, 1976; Andriantsimahavandy et al., 1997; Pal et al., 2000; Carpio, 2002; Nsengiyumwa et al., 2003; Wagner \& Newton, 2009; Winkler et al., 2009; Coyle et al., 2012; Millogo et al., 2012). Evidence from neuroimaging studies in people with epilepsy and the recent meta-analysis and systematic review which included only studies conducted in sub-Saharan Africa demonstrated a significant association between neurocysticercosis and epilepsy, suggesting that neurocysticercosis could be the major 
contributing factor for the high prevalence of epilepsy observed (Carpio et al., 1998; Nsengiyumwa et al., 2003; Quet et al., 2010; Ndimubanzi et al., 2010). The major limitation on establishing evidence on the association of neurocysticercosis and epilepsy in sub-Saharan Africa is the lack of longitudinal surveys to examine the incidence of epilepsy following infections with T. solium (Blocher et al., 2011) or the impact of T. solium treatment using praziquantel on the prevalence of epilepsy.

Echinoccocus species and echinococcosis: Echinococcosis or hydatidosis is a cyclozoonotic infection caused by cestode parasites belonging to the Genus Echinococcus (Gottstein \& Reichen., 2003; Eckert $\&$ Deplazes et al., 2004). Two main species are of medical importance, Echinoccocus granulosus which causes cystic echinococcosis, has a cosmopolitan distribution and is characterized by a remarkably wide range of intermediate hosts; and Echinococcus multilocularis, the causative agent of alveolar echinococcosis, which is restricted to the northern hemisphere (Gottstein \& Reichen., 2003;Eckert \& Deplazes et al., 2004). The definitive hosts of E. granulosus or E. multilocularis are carnivorous animals and become infected after consuming the offals from infected intermediate hosts, mainly wild or domesticated ungulates (Gottstein \& Reichen, 2003; Eckert \& Deplazes et al., 2004; Ndimubanzi et al., 2010). Digestion of the cysts releases the larval forms, the protoscolices, which evaginate and attach to the intestinal wall and develop into adult stages (Gottstein \& Reichen, 2003; Eckert \& Deplazes et al., 2004; Ndimubanzi et al., 2010). Humans are accidental hosts and are infected via contaminated water or vegetables (Matossian et al., 1977; Huttner et al., 2009). Within the human host, eggs are digested and the larval forms, so-called oncospheres, are released. They penetrate the intestinal muscular layers, gain access to the blood system, especially the portal veins, and are transported to various body organs (Matossian et al., 1977;Turgut, 1997; Gottstein \& Reichen, 2003; Eckert \& Deplazes et al., 2004; Huttner et al., 2009; Huttner et al., 2009; Ndimubanzi et al., 2010; Ernest et al., 2010).Filtration of the oncospheres occurs in the liver and the lungs and about $60-70 \%$ and $10-15 \%$ of the hydatid cyst are formed in the liver and lungs, respectively (Turgut, 1997; Huttner et al., 2009; Ernest et al., 2010). The involvement of other organs, such as brain, is uncommon but does occur, especially when the liver and lungs fail to filter all the oncosphere in the blood circulation Huttner et al., 2009; Ernest et al., 2010).

The development of cerebral cysts due to E. granulosus occurs very rarely. It is estimated that only $2 \%$ of all echinococcosis cases develop cerebral echinococcosis (Lunardi et al., 1991; M irceuski et al., 2005; Jenkins et al., 2010). The brain sites involved are the cerebral parenchymal and subarachnoid spaces (Lunardi et al., 1991). The size and the pressure exerted by the growing hydatid cyst may result into increased intracranial pressure, focal neurological symptoms, organ dysfunctions and atrophy of the surrounding parenchyma (Lunardi et al., 1991). Evidence from hospital-based case reports from other parts of the world indicates that patients with cerebral hydatid cysts, depending on the size and location of the cysts, may develop generalized tonic clonic seizures secondary to cystic mass as well as raised intracranial pressure (Lunardi et al., 1991). In general, epilepsy appears to be a very rare complication of echinococcosis, as few individuals end up with cerebral echinococcosis. How ever, the lack of advanced imaging techniques in most of the health facilities in sub-Saharan Africa where the disease is endemic could, in part, contribute to the absence of reported cases of cerebral echinococcosis and hence the lack of association between epilepsy and echino coccosis.

\section{Nematodes}

Onchocerca volvulus and onchorcerciasis

Onchocerca volvulus is a filarial worm and is a causative agent of onchorcerciasis or "river blindness" disease in Africa. About 99\%of the 37 million people estimated to be infected with onchorcerciasis live in Africa (Hotez et al., 2008; Hotez Kamath, 2009). The microfilaria and the adult O. volvulus are 
mainly found in the subcutaneous tissues but, occasionally, the microfilariae are seen in the blood, urine and cerebral spinal fluids (Duke et al., 1975; Duke et al., 1976). Human are infected with the third stage larvae (the infective stages) which are injected to human by the vector, Simulium species, when it takes blood meals. In humans, the larvae migrate to subcutaneous tissues, two moults occur and after several months it develop to adult stages. Several mechanisms are thought to contribute to the pathogenesis of onchocerciasis, including autoimmunity and secondary bacterial infections. However, repeated cycles of inflammatory response associated with dead microfilariae in the subcutaneous tissues are responsible for the dermis changes and eye lesions observed (Fuglsang $\&$ Anderson, 1974; Ottesen, 1995; Abiose, 1998; Aliet, 2003).

The possibility of an association between 0 . volvulus infection and epilepsy has been explored in East Africa since 1950s (Hall \& Pearlman, 1999). However, the biological causal relationship between onchorcerciasis and epilepsy remains unclear. The pathological changes which occur in the eye following the death of the microfilariae are thought to damage the optic nerves which in turn may partly reflect the pathological process in the brain (Wagner \& Newton, 2009). However, no study has proven this hypothesis in the epileptic patients co-infected with onchorcerciasis. Another possible explanation could be the entry of microfilariae or adult 0 . volvulus into the CNS and therefore the generation of autoantibodies. Studies have reported the presence of the microfilariae in the cerebral spinal fluids (Kirk et al., 1959; Marin et al., 2006). How ever, no study has evaluated the relationship between the microfilariae in the cerebral spinal fluids and the occurrence of epilepsy. In addition, no neuro-imaging study has illustrated the occurrence of adult worms in the CNS or described the lesions associated with adult O. volvulus in the brain (Duke et al., 1976).

Despite the lack of evidence on the biological causal relationship between 0 . volvulus and epilepsy, epidemiological studies have repeatedly reported a variation in prevalence of epilepsy in individuals living in areas with different transmission intensity of onchorcerciasis. The results of epidemiological surveys in Burundi and Uganda described a significant positive association between prevalence of epilepsy and onchorcerciasis (Kaiser et al., 1996; Newell et al., 1997). In Uganda, Ovuga et al. (1992) reported a high prevalence of epilepsy in an area with high transmission of onchorcerciasis. Another study comparing the prevalence of epilepsy in areas with different transmission intensity of onchorcerciasis, observed a high prevalence of epilepsy in hyperendemic areas of onchorcerciasis, as compared to hypoendemic areas (Kaiser et al., 1996; Kaiser et al., 1998). Equally, case-control studies support the existence of a link between onchorcerciasis and epilepsy (Boussinesq, 2002). A recent systematic review and meta-analysis article, including population-based surveys conducted in sub-Saharan Africa, supports the hypothesis that onchocercaciasis is associated with epilepsy and that epilepsy prevalence increases when onchorcerciasis transmission intensity increases (Pion \& Boussinesq, 2009). Such conclusions have however not been reported by other case control and cross-sectional studies in endemic areas (Druet-Cababnanc, 1997; Pion et al., 2009; Konig et al., 2010). It is worthy to note that this is the only study that has examined cerebral spinal fluid and it has not revealed any evidence of contact of the parasite with the cerebral spinal fluid in the past or at present. Despite the evidence from case control and epidemiological observation studies, the biological causal relationship between onchocerciasis and epilepsy in sub-Saharan Africa is still controversial and further parasitological and neuro-imaging studies are required to resolve the discrepancies between various studies.

Toxocara species and toxocariasis

Toxocariasis is endemic in all parts of the world and is caused by two zoonotic roundworms of dogs and cats, Toxocara canis and T. cati (Magnaval et al., 1997; Despommier., 2003). A high prevalence of toxocara infections has been described in the tropical and sub-tropical areas where the humid 
climate and poor hygiene favour survival of the eggs in soil and the transmission to humans (Magnaval et al., 1994; Overgaauw., 1997; Nicoletti et al., 2007). Humans are accidental hosts and human toxocariasis mainly results from infections with the larval stage of Toxocara canis and follows the ingestion of eggs through contaminated hands and formites (Kabore et al., 1996). The eggs hatch in the gastrointestinal tract and the juvenile stages migrate, enter the portal circulation and then, via the small blood vessels, move to the viscera producing an inflammatory response along the migratory paths, leading to a condition termed as visceral larval migrans (Thompson et al., 1986). A chronic inflammatory response may end up with the formation of a granuloma (Thompson et al., 1986). The juvenile stages may be located in the central nervous system, although this is very uncommon, and produce an inflammatory response leading to a variety of neurological syndromes (Thompson et al., 1986). It has been hypothesized that Toxocara infection is associated with epilepsy, with toxocariasis described as a cofactor for epilepsy (Schantz \& Glickman., 1978; Magnaval et al., 1994). Case control studies conducted in Africa have produced contradicting results (Arpino et al., 1990; Magnaval et al., 1994;Winkler et al., 2008). In Burundi, a case control study among people with epilepsy reported a significant association between positivity rates of T. canis antibodies and epilepsy (Magnaval et al., 1994). The author therefore concluded that T. canis increases the risk of developing epilepsy in endemic areas (Magnaval et al., 1994). A similar result was reported outside Africa in Bolivia and in Italy (Nicoletti et al., 2002). In contrast, comparable study in Tanzania did not observe any relationship between antitoxocarial antibodies and epilepsy (Winkler et al., 2008). The relationship between epilepsy and toxocariasis is still controversial and needs further studies to fill the current gaps of knowledge.

Trichinella spiralis and trichinellosis

Trichinella species are the causative agents of trichinellosis and infect varieties of mammals including human (Nicoletti et al., 2007; 2008; Gottstein et al., 2009). This nematode is distributed worldwide and infections to human are mainly attributed to consumption of raw and undercooked meat, especially from domestic pigs and wild boars (Nicoletti et al., 2007; 2008; Gottstein et al., 2009). In the gastrointestinal tract, the ingested meat is digested and the encysted larvae are released. They penetrate the intestinal mucosa, and migrate to the circulatory and the lymphatic system (Nicoletti et al., 2008; Gottstein et al., 2009). Through the circulatory system, the larvae migrate through all parts of the body but they only survive in the striated muscles where they become encysted and eventually calcify (Murrel \& Pozio., 2000).

Neurotrichinosis occurs in an estimated $0.2 \%$ - 52\% of all symptomatic cases infected with Trichinella spiralis and generally in severely affected patients (Dalessio \& Wolff, 1961; Adams et al., 1997). Other reports indicate that the involvement of the CNS occurs in 10-24\%of the cases with mortality rates reaching $50 \%$ (Hurd, 1953). The involvement of the CNS is mainly characterized by epileptic seizures and psychiatric changes (Kramer \& Aita, 1978). However, further research is needed to support the little evidence available on the role of $\mathrm{T}$. trichiura in causing seizure and epilepsy in tropical countries, especially in sub-Saharan Africa.

\section{Trematodes}

Schistosomiasis: Sub-Saharan Africa is home for $85 \%$ of people infected with intestinal and urogenital schistosomiasis worldwide (Ross et al., 2002; Gryseels et al., 2006). Two species are the major causative agent of schistosomiasis in this setting, namely S. mansoni and S. haematobium (Ross et al., 2002; Gryseels et al., 2006). Infections to humans occur following penetration of the larvae stage cercariae through the skin. After having shed their tails, the cercariae are transformed into schistosomula which migrate passively into the lymphatic system or blood vessels to the heart and then to the lungs (Pittela, 1997; Ross et al., 2002). The schistosomes species have predilection sites in 
the body, S. mansoni residing in the inferior mesenteric veins and S. haematobium in the veins of the vesical plexus (Pittela, 1997). However, the schistosomula stages can also be carried through retrograde venous flow (Batson, 1940) into Baston's vertebral epidural venous plexus (Batson, 1940; Pittela, 1991), which connects the portal venous system and venae cavae to the spinal cord and cerebral veins (Batson, 1940; Scrimgeour \& Gajdusek, 1985; Pittela, 1991).

The pathogenesis of the schistosomiasis of the CNS depends on the location of the eggs, the size of the eggs and the intensity of the host's immune response (Pittela, 1991). The eggs of S. mansoni and S. haematobium are larger in size and are mainly trapped in the spinal cord and thus, infection of the CNS is mainly restricted to the spinal cord and brain (Carod-Artal, 2009; Wu et al., 2012). The immune response against the secreted eggs antigens results into the formation of granulomas at the site of eggs deposition and the formed granuloma mass may result into increased intracranial pressure, erosion of the vascular walls, and focal and generalized seizures (Betting et al., 2005; Carod-Artal, 2009; Wu et al., 2012). The occurrence of seizures is mainly associated with chronic schistosomiasis (Betting et al., 2005; Carod-Artal, 2009; Wu et al., 2012). Histological and autopsy studies have proved the occurrence of neurological involvement in schistosomiasis (Nwokolo., 1974). However, there is a lack of epidemiological evidence on the relationship between epilepsy and schistosomiasis in endemic areas. Epidemiological studies in endemic areas, for both intestinal and urinary schistosomiasis, would demonstrate the actual contribution of schistosomiasis to the burden of epilepsy.

Paragonimus and paragonimiasis

Paragonimiasis is caused by various species of a food-borne trematode of the genus Paragonimus, commonly referred to as lung flukes (Moyou-Somo et al., 2003; WHO, 2005; N'da et al., 2008). There are about 40 species of the parasites but only ten are highly pathogenic to human (Moyou-Somo et al., 2003; WHO, 2005; N'da et al., 2008). In Africa, the endemic foci are mainly located around the Guinean Gulf and in the central part of the continent (M oyou-Somo et al., 2003; WHO, 2005; N'da et al., 2008).

Human infection occurs following the ingestion of undercooked infected freshwater crustaceans (including crayfishes and crabs) infected with metacercariae (Cha et al., 1994). In the gastrointestinal tract, the metacercariae excyst and the released juvenile worms penetrate the intestinal muscles and migrate through the peritoneal and pleural cavity to the lungs (Cha et al., 1994). The primary predilection site is the lung and extra-pulmonary location of the adult parasites may involve the brain, which can present with severe manifestations, including epileptic seizures (Cha et al., 1994; Yin \& Shin, 2002). In the brain, the predilection sites for the parasites are the occipital and temporal lobes (Yin \& Shin, 2002; Beers \& Berkow, 2002). To our knowledge, cases of cerebral paragonimiasis are very rare or have not been reported in Africa. Evidence from other part of the world where the disease is endemic indicate that cerebral paragonimiasis occurs in about 20\%$45 \%$ of the individuals with erratic paragonimiasis (Yin \& Shin, 2002; Lee et al., 2006). Hospital-based reports indicate that 3.5\% of the patients with erratic food-borne encephalopathy are affected by cerebral paragonimiasis (Beers \& Berkow, 2002). The pathogenesis of the epilepsy secondary to paragonimiasis is mainly due to increased intracranial pressure or cerebral calcification and production of proteases which may cause brain damage and interfere with neuronal transmission (Beers \& Berkow, 2002; Lee et al., 2006). The lack of evidence in Sub-Saharan Africa calls for further research on the contribution of the Paragonimus species in causing epilepsy.

\section{Protozoa}

Plasmodium falciparum and falciparum malaria 
In sub-Saharan Africa, Plasmodium falciparum is the only malaria parasite responsible for all the neurological complications, including cerebral malaria (Taratuto et al., 1997). The WHO defines cerebral malaria as an unarousable coma in individuals with $P$. falciparum malaria when other causes of encephalopathy have been excluded (Beales et al., 2000; M ishara \& Newton, 2009; Kariuki et al., 2011). The pathogenesis of cerebral malaria due to $P$. falciparum mainly involves sequestration of the infected erythrocytes to the endothelial cells of the microvasculature of the brain (Murphy $\&$ Breman, 2001; Idro et al., 2005). In addition, sequestration may occur as a consequence of cytoadherence of the infected erythrocytes to endothelial cells and may also be increased when adherent infected erythrocytes bind other infected erythrocytes (autoagglutination) or uninfected erythrocytes (rosseting) (Robets et al., 1992; Lou et al., 2001). Binding of the parasites or infected erythrocytes to the endothelial cells of the microvasculature of the brain is mediated by a group of variant surface antigens expressed at the surface of the infected erythrocytes, which in P. falciparum is described as Plasmodium falciparum erythrocyte membrane protein-1(PfEM P1) (Robets et al., 1992; Lou et al., 2001). The consequence of sequestration is the reduction or obstruction of the microvascular flow to the brain. Furthermore, deformability of the infected erythrocytes affects the flow of these cells in the microvasculature and hence affects the blood flow (Robets et al., 1992; Lou et al., 2001). The effects of microvasculature obstructions of the blood flow are the reduction in oxygen and other important substrate supply to the brain which results into anaerobic glycolysis, lactic acidosis and cellular dysfunction (Robets et al., 1992; Lou et al., 2001). Thus, in African children, cerebral malaria is mainly characterized with coma, convulsions, acidosis, hypoglycaemia and severe anaemia (Taratuto et al., 1997).

In endemic areas of sub-Saharan Africa, the frequency of seizure due to P. falciparum malaria is about $80 \%$ (White, 1999), with half of the children hospitalized with falciparum malaria reported to have seizures like symptoms (Idro et al., 2010). Epileptic seizures are the most frequent manifestation of central nervous system (CNS) involvement (Taratuto et al., 1997). Seizures may occur during the acute phase of the disease, which may be either focal (with or without secondary generalization) or generalized (Taratuto et al., 1997; Idro et al., 2010). Multiple and prolonged seizures are associated with increased mortality and neurological and cognitive deficits (Taratuto et al., 1997; Ngoumgou \& Preux, 2008; Idro et al., 2010). The status epilepticus due to falciparum malaria is mainly associated with severe intracranial hypertension with evidence of brain swelling on Computerized Tomography (CT) (Ngoumgou \& Preux, 2008; Idro et al., 2010).

There is a substantial gap of knowledge on the incidence of post-malaria epilepsy. The available evidence indicates that epilepsy occurs as a sequel in about $10 \%$ of the individuals who recovered from cerebral malaria (White, 1999). Other studies have reported higher prevalence of epilepsy in children with prior history of cerebral malaria, as compared to those unexposed to cerebral malaria (Ngoumgou \& Preux, 2008; Dulac, 2010). In addition, the age-adjusted relative risk for developing epilepsy after exposure to cerebral malaria shows a strong association between epilepsy and cerebral malaria (Carter et al., 2001; Ngoumgou \& Preux, 2008). There is a biological causal relationship between cerebral malaria and epilepsy (Ngoumgou \& Preux, 2008), however, further systematic studies are needed to prove the hypothesized causal relationship.

Toxoplasma gondii and toxoplasmosis

Toxoplasma gondii is an obligate intracellular protozoan parasite which is zoonotic and distributed worldwide (Montoya \& Liesenfeld, 2004; Carruthers \& Suzuki., 2007). An estimated one third of the world population is infected with toxoplasmosis (Carruthers \& Suzuki., 2007). Humans acquire infection through various ways: (i) by ingestion of the T. gondii bradyzoites in infected undercooked meat, (ii) by ingestion of the T. gondii infectious oocysts present in contaminated hands and water/soil contaminated by cats faeces, (iii) by congenital trans-placental transmission of tachyzoites 
from mothers during pregnancy and (iv) by organ transplantation (Da Gama et al., 2004). The third mode of transmission often results into severe neurological and ophthalmologic disease (Da Gama et al., 2004). Ingested bradyzoites multiply and traverse the placental or the intestinal epithelium and enter circulating cells such as the macrophages or dendritic cells. They may gain access to the brain and form dormant cysts (Sims et al., 1989; Baragan \& Sibley, 2002; Lambert et al., 2006). Proliferating T. gondii tachyzoites have been identified in glial cells and Purkinje cell in human patients who developed toxoplasmosis encephalitis (Powell et al., 1978; Palmer, 2007).

It has been postulated that T. gondii infection is associated with cryptogenic epilepsy (epilepsy of unknown causes) in endemic areas (Tenter et al., 2000; Stommel et al., 2001; Yazar et al., 2003; Zibaei et al., 2011). The proposed mechanism through which T. gondii causes epilepsy has been described in details elsewhere (Stommel et al., 2001). To our knowledge, the number of studies investigating the potential contribution of T. gondii to epilepsy is very limited in sub-Saharan Africa. However, evidence from case control and ecological studies from other parts of the world reports a possibility that cryptogenic epilepsy may be a consequence of latent toxoplasmosis infections (Tenter et al., 2000; Stommel et al., 2001; Yazar et al., 2003; Zibaei et al., 2011). In support of this hypothesis, observational studies have reported a decline in incidence of cryptogenic epilepsy and toxoplasmosis with time (Potasman et al., 1995; Yazar et al., 2003; Schuster \& Visvesvara, 2004). Mostly as a consequence of improved nutrition and personal hygiene and public health education to risk groups (Stommel et al., 2001). Despite the fact that the association between T. gondii and epilepsy looks plausible, there are many confounding factors (i.e. age, socioeconomic status and education level) which need to be addressed by larger case control or longitudinal studies. As a matter of fact, epilepsy in individuals infected with toxoplasmosis could be caused by other agents rather than T. gondii.

Intestinal amoebas and free living amoebas

Human pathogenic free living amoebas (Naegleria fowleri, Acanthamoeba species and Balamuthia mandrillaris) and parasitic amoebas (Entamoeba histolytica/Entamoeba dispar) cause various forms of clinical manifestations, the most fatal form being encephalitis (Maldonado et al., 2012). The spread of Entamoeba histolytica to human populations occurs through the faecal-oral route, via water and food contaminated with cysts. The ingested cysts germinate in the intestines, multiply by nuclear division and colonize the colon and caecum (Maldonado et al., 2012). Extra-intestinal amoebiasis, which occurs following the perforation of the intestinal walls, is the source of infection to other body tissues, such as the liver and brain (Becker et al., 1980; Martinez \& Visvesvara, 1997). Cerebral amoebiasis is a rare form of invasive disease with a high case fatality rate, presenting with brain abscess, meningitis symptoms, focal signs and seizures (Becker et al., 1980; Martinez \& Visvesvara, 1997). Neurological signs and symptoms are mainly related to increased intracranial pressure. However, epidemiological data describing the incidence of epileptic seizure associated with Entamoeba histolytica are insufficient, in particular from areas where E. histolytica is highly endemic.

Naegleria fowleri is the agent of a prominent parasitic infection of the brain and the spinal cord (Schoeman et al., 1993). It is the cause of primary amoebic meningoencephalitis (PAM), which is acquired during swimming or other water-related activities. In addition, inhalation of the trophozoites/cysts from dust or air is another way of acquiring the infection (Schoeman et al., 1993). The parasite gains access to the olfactory neuroepithelium and travels to the mesaxonal spaces of the unmyelinated fila olfactoria of the olfactory, crosses the cribriform plate and reaches the subarachnoid space where it continues to multiply and proliferate (Schoeman et al., 1993). The parasites attack the olfactory and frontal lobes, the base of the brain, the brain stem. In later stages, they cause necrosis of the CNS through ingestion of the brain tissues (Schoeman et al., 1993). Seizures and other neurological signs are commonly associated with PAM (Schoeman et al., 1993: 
Cetin \& Blackal., 2012). The majority of the PAM has been reported from the USA and only few cases have been reported from sub-Saharan Africa (Lawande et al., 1980; Ygonabo et al., 1989; Schoeman et al., 1993)

Acanthamoeba species are the causative agents of granulomatous amoebic encephalitis (GAE), with no involvement of the meningeal layer (Lorenzo-M orales et al., 2006 Siddiqui, R. \& Khan, 2012). The parasite may also invade other body organs/tissues such as lungs, skin or eye lenses and causes pneumonitis, dermatitis and keratitis (Schoeman et al., 1993; Lorenzo-Morales et al., 2006; Siddiqui, R. \& Khan, 2012). The initial infection may occur through cut wounds in the skin that become contaminated with soil or though inhalation of the trophozoites/cysts into the respiratory tract (Martinez \& Visvesvara., 1997; Siddiqui \& Khan, 2012). From the point of entry, the trophozoites or cysts are disseminated throughout the body via the blood circulation and reach the central nervous system, where they cause GAE (Schoeman et al., 1993; Martinez \& Visvesvara, 1997; Siddiqui \& Khan, 2012). The areas of the brain mostly affected are the cerebrum, cerebellum and brain stem (Schoeman et al., 1993). Granulomatous amoebic encephalitis appears to be mostly related to the response of the host immunity to the trophozoites/cysts (Siddiqui \& Khan, 2012). In sub-Saharan Africa, isolation of Acanthamoeba species from the environment and animals has been reported (Ndiaye et al., 2005; Lorenzo-M orales et al., 2006). Human cases of Acanthomeba species involving the brain have also been described (Ndiaye et al., 2005).

\section{Conclusion}

Though several epidemiological and case control studies indicate a relationship between parasitic agents and epilepsy in sub-Saharan Africa, there remains a considerable gap of knowledge on the exact nature and magnitude of the association. Evidence on the incidence of epilepsy following initiation of parasitic infections from longitudinal studies is lacking. There is insufficient evidence on reduction of epilepsy following specific treatment or control of parasitic infections. Thus, there is an urgent need for systematic epidemiological studies to understand the burden of epilepsy in areas endemic due to preventable parasitic infections, to prove a causal relationship, and to understand the impact of controlling these parasitic diseases on reduction of the burden of epilepsy. There are a number of confounding factors to be addressed and eventually ruled out by longitudinal or case control studies. This will allow a better definition of attributable risks for epilepsy due to parasitic infections and a better estimation of the incidence, morbidity and mortality of epilepsy due to infectious causes.

Co-infection of parasitic infections and epilepsy in sub-Saharan Africa are common, particularly in areas characterized by poor hygiene standards. There is an epidemiological link on the association between epilepsy and various parasitic infections. However, the biological causal relationship requires further investigation in adequately designed studies.

\section{Conflicts of interest}

Non-declared

\section{Reference}

Abiose, A. (1998) Onchocercal eye disease and the impact of Mectizan treatment. Annals of Tropical Medicine and Parasitology 92, S11-S22.

Adamolekun, B. (1995) The aetiologies of epilepsy in tropical Africa. Tropical Geographical Medicine47, 115-17. 
Adams, RD., Victor, MV. \& Ropper, AH. (1997) Infections of the nervous system. In: Adams RD, Victor MV, Ropper AH eds. Principles of neurology. Sixth edition. New York: McGraw Hill: pp 695741

Adeloye, A. (1976) Post-traumatic epilepsy in missile head injury. Medicine Afrique Noire 23, 429-431

Adeuja, A., Kale, O., Adeyefa, A., Bademosi, O., Olumide, A., Oyediran, ABO., Pearson, C.A. \& Bolis, C.L.(1982) Research protocol for measuring the prevalence of neurological disorders in developing countries, results of a pilot study in Nigeria. Neuroepidemiology 1, 143-153.

Ali, M.M., Baraka, O.Z., AbdelRahman, S.I., Sulaimain, S.M., Williams, J.F., Homeida, M.M. \& Mackenzie, C.D. (2003) Immune response directed against microfilariae correlate with severity of clinical onchodermatitis and treatment history. The Journal of Infectious Diseases 187, 714-717.

Amogne, W., Teshager, G. \& Zenebe, G. (2006) Central nervous system toxoplasmosis in adult Ethiopians. Ethiopia Medical Journal 44, 113-120.

Andrade, Z.A. (2009) Schistosomiasis and liver fibrosis. Parasite Immunology31, 656 - 663.

Andriantsimahavandy, A., Lesbordes, J.L., Rasoaharimalala, B., Peghini, M., Rabarijaona, L., Roux, J . \& Boisier, P. (1997) Neurocysticercosis: a major aetiological factor of late onset of epilepsy in Madagascar. Tropical Medicine and International Health 2, 741-746.

Arpino, C., Gattinara, G.C., Piergili, D. \& Curatolo, P. (1990) Toxocara infection and epilepsy in children: a case control study. Epilepsia 31, 33-36.

Asanin, B., Milic, I. \& Milovic, Z. (2008) Echinococcosis cerebri: report of two less common cases. FACTA UNIVERSITATIS Series: Medicine and Biology 15, 2, 64 - 67.

Barragan, A. \& Sibley, L.D. (2002) Transepithelial migration of Toxopalsma gondii is linked to parasites motility and virulence. Journal of Experimental Medicine 195, 1625-1633.

Batson, O.V. (1940) The function of the vertebral veins and their role in the spread of metastases. Annals of Surgery 112, 138-149.

Beales, PF., Brabin, B. \& Dorman, E. (2002) Severe falciparum malaria. WHO, Communicable disease cluster.1211 Geneva 27, Switzerland. Transactions of the Royal Society of Tropical Medicine and Hygiene, 94 (Suppl 1), S1-90.

Becker, GL J r., Knep, S., Lance, KP. \& Kaufman, L. (1980) Amebic abscess of the brain. Neurosurgery 6, 192-194.

Beers, M.H. \& Berkow, R. (2002) The Merck Manual of Diagnosis and Therapy. $17^{\text {th }}$ edition. Rahway, NJ : Merck Research Laboratories.

Betting, L.E., Pirani, C., Quciroz, L.S., Damasceno, B.P. \& Cendes, F. (2005) Seizures and cerebral schistosomiasis. Archives of Neurology 62, 1008-1010.

Bittencourt, P.R., Sander, J.W. \& Mazer, S. (1999) Viral, bacterial, fungal and parasitic infections associated with seizure disorders. In: Meinardi H, editor. Handbook of Clinical Neurology, volume 12. Amsterdam: Elsevier Sciences, page, 145-174. The Epilepsies.

Blocher, J., Schmutzhard, E., Wilkins, P.P., Gupton, P.N., Schaffert, M., Auer, H., Gotwald, T., Matuja, W. \& Winkler, A.S. (2011) A cross-sectional study of people with epilepsy and neurocysticercosis in Tanzania: clinical characteristics and diagnostic approaches. PLOS Neglected Tropical Diseases 5, 6, e1185.

Boussinesq, M., Pion, S.D.S., Demanga-Ngangue, \& Kamgno, J. (2002) Relationship between onchocerciasis and epilepsy: a matched case-control study in the Mbam Valley, Republic of Cameroon. Transactions of the Royal Society of Tropical Medicine and Hygiene 96, 537-541

Burneo, J.G., Tellez-Zentenol, J. \& Wiebe, S. (2005) Understanding the burden of epilepsy in Latin America: a systemic review of its prevalence and incidence. Epilepsy Research $66,63-74$.

Carod-Artal, F.J . (2009) Tropical causes of epilepsy. Review of Neurology1-15, 49, 475-482.

Carpio, A. (2002) Neurocysticercosis: an update: Lancet Infectious Diseases 2, 751-762. 
Carpio, A., Escobar, A. \& Hauser, W.A. (1998) Cysticercosis and epilepsy: a critical review. Epilepsia 39, $1025-1040$.

Carruthers, V.B. \& Suzuki, Y. (2007) Effects of Toxopalsma gondii infection on the brain. Schizophrenia Bulletin 33, 745-751

Carter, J .A., Neville, B.G. \& White, S. (2004) Increased prevalence of epilepsy associated with severe falciparum malaria in children. Epilepsia 45, 978-981

Cetin, N. \& Blackall, D. (2012) Naegleria fowleri meningoencephalitis. Blood 1199,3658.

Cha, S.H., Chang, K.H., Cho, S.Y., Han, M.H., Kong, Y., Suh, D.C., Choi, C.G., Kang, H.K. \& Kim, M.S.(1994) Cerebral paragonimiasis in early active stage: CT and MR features. American Journal of Roentgenology 162,141-145.

CTDILAE (1994) Commission on Tropical Diseases of the International League Against Epilepsy. Relationship between epilepsy and tropical diseases. Epilepsia 35, 89-93.

Coyle, C.M., Mahanty, S., Zunt, J .R., Wallin, M.T., Cantey, P.T., White, C.A.C., O'Neal, S.E., Serpa, J .A., So uthern, P.M., Wilkins, P., M cCarthy, A.E., Higgs, E.S. \& Nash. T.E. (2012) Neurocysticercosis: Neglected but not forgotten. PLOS Neglected Tropical Diseases 6, e1500.

Da Gama, L.M., Ribeiro-Gomes, F,L., Guimaraes, U. Jr. \& Arnholdt, A.C. (2004) Reduction in adhesiveness to extracellular matrix components, modulation of adhesion molecules and in vivo migration of murine macrophages infected with Toxoplasma gondii. Microbes and Infections 6, 1287-1296.

Dalessio, D.J . \& Wolff, H.C. (1961) Trichinella spiralis infection of the central nervous system. Archives of Neurology 4,407-417.

De Bittencourt, P.R.M., Adamolekun, B., Bharucha, N., Carpio, A., Danesi, M.A., Dumas, M., M einardi, H., Ordinario, A., Sennayake, N., Shakir, R. \& Sotelo, J. (1996) Epilepsy in the tropics: I. Epidemiology, socioeconomic risk factors, and etiology. Epilepsia 37, 1121-1127.

De Bittencourt, P.RM., Gracias, C.M. \& Lorenzana, P. (1988) Epilepsy and parasitosis of the central nervous system. In: Pedley, T.A., M eldrum, B.S. (eds). Recent Advances in Epilepsy. New York: Churchill Livingstone, 123-159.

Dent, W., Helbok, R., Matuja, W.B.P., Scheunemann, S. \& Schmutzhard, E. (2005) Prevalence of active epilepsy in a rural area in South Tanzania: A door-to-door survey. Epilepsia, 46, 1963-1969.

Despommier, D. (2003) Toxocariasis: Clinical Aspects, Epidemiology, Medical Ecology, and Molecular Aspects. Clinical Microbiology Reviews 16, 265-272.

Druet-Cabanac, M., Preux, P.M., Bouteille, B., Bernet-Bernady, P., Dunand, J., Hopkins, A., Yaya, G., Tabo, A., Sartoris, C., Macharia, W. \& Dumas, M. (1999) Onchocerciasis and epilepsy: a matched case-control study in the Central African Republic. American J ournal of Epidemiology 149, 565-570.

Duke, B.O., Moore, P.J. \& Vincelette, J. (1975) Factors influencing the passage of Onchocerca volvulus microfilariae into the urine. Tropen-medizin und Parasitologie 26, 449-468.

Duke, BO., Vincelette, J. \& Moore, P.J. (1976) The population dynamics of Onchocerca volvulus microfilariae during treatment with suramin and diethylcarbamazine. Tropen-medizin und Parasitologie 27, 133-144.

Duke, B.O., Vincelette, J. \& Moore, P.J. (1976) Microfilariae in the cerebrospinal fluid, and neurological complications, during treatment of onchocerciasis with diethylcarbamazine. Tropen-medizin und Parasitologie 27, 123-132.

Dulac, 0. (2010). Cerebral malaria and epilepsy. Lancet Neurology 9,12, 1144-1145.

Eckert, J. \& Deplazes, P. (2004). Biological, epidemiology and clinical aspects of Echinococcosis: a zoonosis of increa sing concern. Clinical Microbiology Review 17, 107-135.

Elnahas, A., Gerais, A.S., Elbashir, MI., Eldien, E.S. \& Adam, I. (2003) Toxoplasmosis in pregnant Sudanese women. Saudi Medical Journal 24,868-870. 
Epilepsy and Driving in Europe (2005) A report of the Second European Working Group on Epilepsy and Driving, 2005.

Ernest, E., Nonga, H.E., Kynsieri, N. \& Cleaveland, S. (2010) A retrospective survey of human hydatidosis based on hospital records during the period 1990-2003 in Ngorongoro, Tanzania. Zoonoses and Public Health 57, e124-e129.

Falusi, O., French, A.L., Seaberg, E.C., Tien, P.C., Watts, D.H., Minkoff, H., Piessens, E., Kovacs, A., Anastos, K. \& Cohen, M.H. (2002) Prevalence and predictors of Toxoplasma seropositivity in Women with and at Risk for Human Immunodeficiency Virus Infection. Clinical Infectious Diseases 35, 1414-1417.

Faust, E.C., Russel, P.F. \& J ung, R.C. (1979) Cysticercosis. In: Fasut EC, eds. Advances in Parasitology. Philadelphia: Lea and Febiger, 529-35

Fisher, R.S., van Emde Boas, W., Blume, W., Elger, C., Genton, P., Lee, P. \& Engel, J . J r. (2005) Epileptic seizures and epilepsy: definitions proposed by the International League Against Epilepsy (ILAE) and the International Bureau for Epilepsy (IBE). Epilepsia 46, 470-472.

Forsgren, L. (2008) Estimations of the prevalence of epilepsy in sub-Saharan Africa. Lancet Neurology 7, 21-22.

Forsgren, L., Beghi, E., Oun. A. \& Sillanpää, M. (2005) The epidemiology of epilepsy in Europe - a systematic review. European J ournal of Neurology 12, 245-253.

Fuglsang, H. \& Anderson, J. (1974) M icrofilariae of Onchocerca volvulus in blood and urine before and after treatment with diethylcarbamazine. J ournal of Helminthology 48, 93-97.

Garcia, HH. \& Modi, M. (2008) Helminthic parasites and seizures. Epilepsia 49, 25-32.

Garcia-Martin, G., Perez-Errazquin, F., Chamorro-Munoz, M.I., Romero-Acebal, M., Martin-Reyes, G. \& Dawid-M ilner, M.S. (2012) Prevalence and clinical characteristics of epilepsy in the South of Spain. Epilepsy Research 102, 100-108.

Gemmell, M.A. \& J ohnstone, P.D. (1978) Factors regulating tapeworms populations: dispersion of eggs of Taenia hydatigena on pastures. Annals of Tropical Medicine and Parasitology 70, 431

Gottstein, B. \& Reichen, J. (2003) Echinococcosis/Hydatidosis. In: Manson's Tropical Diseases, $21^{\text {st }}$ edition, Cook, G.C., Zumla, A. eds, Elsevier Science, London. pp 1561- 1582.

Gottstein, B., Pozio, E. \& Nockler, K. (2009) Epidemiology, diagnosis, treatment and control of trichinellosis. Clinical Microbiological Reviews 22, 127-145.

Gryseels, B., Polman, K., Clerinx, J . \& Kesterns, L. (2006) Human schistosomiasis. The Lancet 368, 1106 - 1118.

Hall, L.R. \& Pearlman, E. (1999) Pathogenesis of Onchocercal keratitis (River Blindness). Clinical Microbiology Reviews 12, 445-453.

Hauser, W.A. \& Kurland, L.T. (1975) The epidemiology of epilepsy in Rochester, Minnesota, 1935 1967. Epilepsia 16, 1-66.

Hook, E.B. \& Regal, R.R. (1995) Capture-recapture methods in epidemiology: methods and limitations. Epidemiology Reviews, 17, 243-264.

Hotez, J. \& Kamath, A. (2009) Neglected tropical diseases in Sub-Saharan Africa: Review of their prevalence, distribution and disease burden. PLoS Neglected Tropical Disease 3,e412.

Hotez, P.J., Brinkley, P.J ., Bethony, J.M., King, C.H., Pearce, E.J . \& Jacobson, J. (2008) Helminth infections: the great neglected tropical diseases. J ournal of Clinical Investigation 118, 1311-1321

Houinato, D., Yemadje, L.P., Glitho, G., Adjien, C., Avode, G., Druet-Cabanac, M. \& Preux, P.M. (2013) Epidemiology of epilepsy in rural Benin: Prevalence, incidence, mortality, and follow-up. Epilepsia doi: 10.1111/epi.12082.

Hurd, R.W. (1953) Focal cerebral injury due to Trichinella spiralis. Journal of Nervous and Mental Diseases 17, 526-536. 
Huttner, M., Sifert, L., Mackenstedt, U. \& Romig, T. (2009) A survey of Echinococcus species in wild carnivores and livestock in East Africa. International J ournal for Parasitology 1269 - 1276.

Idro, R., Jenkins, N.E. \& Newton, C.R.J.C. (2005) Pathogenesis, clinical features, and neurological outcome of cerebral malaria. Lancet Neurology 4, 827-840.

Idro, R., Marsh, K., J ohn, C.C. \& Newton, C.R. (2010) Cerebral malaria: mechanism of brain injury and strategies for improved neuro-cognitive outcome. Pediatric Research 6, 267-274.

J enkins, D.J ., Romig, T. \& Thompson, R.C. (2005) Emergence/re-emergence of Echinococcus spp. - a global update. International J ournal of Parasitology 35, 1205-1219.

Johnson, M.R. \& Sander, J.W. (2001) The clinical impact of epilepsy genetics. Journal of neurology, Neurosurgery and Psychiatry 70, 428-430.

Kabore, J.K., Cabore, J.W., M elaku, Z., Druet-Cabanac, M. \& Preux, P.M. (1996) Epilepsy in a focus of onchorcerciasis in Burkina Faso. Lancet 347, 836.

Kaiser, C., Asaba, G., Leichsenring, M. \& Kabagambe, G. (1998) High incidence of epilepsy related to onchorcerciasis in West Uganda. Epilepsy Research 30, 247-251

Kaiser, C., Kipp, W., Asaba, G., Mugisa, C., Kabagambe, G., Rating D. \& Leichsenring, M. (1996) The prevalence of epilepsy follows the distribution of onchorcerciasis in a West Ugandan focus. Bulletin of the World Health Organization 74, 361-367.

Kaiser, C., Pion, S. \& Boussunesq, M. (2010) Do helminths cause epilepsy? The case of Onchocerca volvulus. Parasite Immunology 32, 79-80.

Kaiser, C., Rubaale, T., Tukesiga, E., Kipp, W., Kabagambe, G., Ojony, J.O. \& Asaba, G. (2011) Association between onchorcerciasis and epilepsy in the Itwara hyperendemic focus, West Uganda: Controlling for time and intensity of exposure. American J ournal of Tropical Medicine and Hygiene 85, 225-228.

Kariuki, S.M., Ikumi, M., Ojal, J ., Sadarangani, M., Idro, R., Olotu, A., Bejon, P., Berkley, J .A., M arsh, K. $\&$ Newton, C.R.J . (2011) Acute seizures attributable to falciparum malaria in an endemic area on the Kenyan coast. Brain 1-10.

Kipp, W., Kasoro, S. \& Burnham, G. (1994) Onchocerciasis and epilepsy in Uganda. Lancet 343, 183184.

Kirk, R., Morgan, H.V., Haseeb, M.A. \& Satti, M.H. (1959) Onchocerciasis in the Sudan Republic. Annals of Tropical Medicine and Parasitology 53, 97-20.

König, R., Nassri, A., Meindi, M., Matuja, W., Kidunda, A.R., Siegmund, V., Bretzel, G., Loscher, T., Jilek-Aall, L., Schmutzhard, E. \& Winkler, A.S. (2010) The role of Onchocerca volvulus in the development of epilepsy in a rural area of Tanzania. Parasitology 137, 10, 1559- 1568.

Kramer, M.D. \& Aita, J .F. (1978) Trichinosis: Infections of the central nervous system, In: Handbook of Clinical Neurology. Vinken, B.J ., Bruyn, G.W. (eds), 35, pp. 267-290.

Lambert, H., Hitziger, N., Dellacasa, I., Svensson, M. \& Barragan, A. (2006) Induction of dendritic cell migration upon Toxoplasma gondii infection potentiates parasites dissemination. Cell and Microbiology 8, 1611-1623.

Lawande, R.V., Macfarlane, J.T., Weir, W.R. \& Awunor-Renner, C. (1980) A case of primary amebic meningoencephalitis in a Nigerian farmer. American J ournal of Tropical Medicine and Hygiene, $29,21-25$.

Lee, J.C., Cho, G.S., Kwon, J.H., Shin, M.H., Lim, J.H. \& Kim, W.K. (2006) Macrophageal/microglial cell activation and cerebral injury induced by excretory-secretory products secreted by Paragonimus westermani. Neurosciences Research 54, 133-139.

Longe, A.C. \& Osuntokun, B.O. (1989) Prevalence of neurological disorders in Udo, a rural community in southern Nigeria. Tropical Geographical Medicine 41, 36-40. 
Lorenzo-Morales, J., Lopez-Darias, M., Martinez-Carretero, E., Valladares, B. (2007) Isolation of potentially pathogenic strains of Acanthamoeba in wild squirrels from the Canary Islands and Morocco. Experimental Parasitology 117, 74-79.

Lorenzo-Morales, J., Ortega-Rivas, A., Martinez, E., Khoubbane, M., Artigas, P., Periago, M.V., Foronda, P., Abreu-Acosta, N., Valladares, B. \& Mas-Coma, S. (2006) Acanthamoeba isolates belonging to T1, T2, T3, T4 and T7 genotypes from environmental freshwater samples in the Nile Delta region, Egypt. Acta Tropica 2, 63-69.

Lou, J., Lucas, R. \& Grau, GE. (2001) Pathogenesis of Cerebral Malaria: Recent Experimental Data and Possible Applications for Humans. Clinical Microbiology Reviews 14, 4810-4820.

Lunardi, P., Missori, P., Di Lorenzo, N. \& Fortuna, A. (1991) Cerebral hydatidosis in childhood: a retrospective survey with emphasis on long-term follow-up. Neurosurgery 29, 515-518.

Magnaval, J.F., Galindo, V., Glickman, L.T. \& Clanet, M. (1997) Human toxocara infection of the central nervous system and neurological disorders: a case control study. Parasitology 115, 537543.

Magnaval, J .F., M ichault, A., Calon, N. \& Charlet, J.P. (1994) Epidemiology of human toxocariasis in La Reunion. Transactions of the Royal Society of Tropical Medicine and Hygiene 88, 531-533.

Maldonado-Barrera, C.A., Campos-Esparza, M.R., Munoz-Fernandez, L., Victoria-Hernandez, J.A., Campos-Rodriguez, R., Talamas-Rohana, P. \& Ventura-Juarez, J. (2012) Clinical case of cerebral amebiasis caused by E. histolytica. Parasitology Research 110, 1291-1296.

Marin, B., Boussinesq, M., Druet-Cabanac, M., Kamgno, J., Bouteille, B. \& Preux, P.M. (2006) Onchocerciasis-related epilepsy? Prospects at a time of uncertainty. Trends in Parasitology 22, $17-20$.

Martinez, A.J . \& Visvesvara, G.S. (1997) Free-living, Amphizoic and opportunistic Amebas. Brain Pathology 7, 583-598.

Matossian, R.M., Rickard, M.D. \& Smyth, J.D. (1977) Hydatidosis: a global problem of increasing importance. Bulletin of the World Health Organization 55, 499-507.

Millogo, A., Nitiema, P., Carabin, H., Boncoeur-M artel, M.P., Rajshekhar, V., Tarnagda, Z., Praet, N., Dorny, P., Cowan, L., Ganaba, R., Hounton, S., Preux, P.M. \& Cisse, R. (2012) Prevalence of neurocysticercosis among people with epilepsy in rural areas of Burkina Faso. Epilepsia 53. 2194-2202.

Mircevski, M. (1989) Surgical treatment of cerebral echinococcosis using the Dowling technic. Acta Chirurgica lugoslavica 36, 617-621

Mishra, SK., \& Newton, C.R. (2009) Diagnosis and management of the neurological complications of falciparum malaria. National Review of Neurology 5, 189-198.

Montoya, J.G. \& Liesenfeld, O. (2004)Toxoplasmosis. The Lancet 363, 1965-1976.

Moyou-somo, R., Kefie-Arrey, C., Dreyfuss, G. \& Dumas, M. (2003) An epidemiological study of pleuropulmonary paragonimiasis among pupils in the per-urban zone of Kumba town, Meme division, Cameroon. BMC Public Health 3, 40.

Murphy, S.C. \& Breman, J.G. (2001) Gaps in the childhood malaria burden in Africa: cerebral malaria, neurological sequelae, anaemia, respiratory distress, hypoglycemia and complications of pregnancy. American J ournal of Tropical Medicine and Hygiene 64, (Suppl 1-2), 57-67.

Murrell, K.D. \& Pozio, E. (2000) Trichinellosis: the zoonosis that won't go quietly. International J ournal for Parasitology 30, 1339-1349.

N'da, A.A., Adoubryn, K., Rondelaud, D. \& Dreyfuss, G. (2008) Human paragonimiasis in Africa. Annals of African Medicine 7,153-162.

Nash, T.E. \& Garcia, H.H. (2011) Diagnosis and treatment of neurocysticercosis. National Review of Neurology, 13, 584-594. 
Ndiaye, M., Diop, A.G., Dieng, Y., Seydi, M., Diouf, F.S., Diop, B.M. \& Ndiaye, I.P. (2005) A case of meningoencephalitis caused by Acanthamoeba sp. in Dakar. Medecine Tropicale (Mars) 65, 6768.

Ndimubanzi, P.C., Carabin, H., Budke, C.M., Nguyen, H., Quan, Y.J., Rainwater, E., Dickey, M., Reynolds, S. \& Stoner, J.A. (2010) A systematic review of the frequency of neurocysticercosis with a focus on people with epilepsy. PLOS Neglected Tropical Diseases 4, e870.

Neto, M.C. \& De Bittencourt, P.R.M. (1996) Infections and post-infective causes. In: Wallace, S., ed. Epilepsy in Children. Madras: Chapman \& Hall, 79-86.

Newell, E.D., Vyungimana, F. \& Bradley, J.E. (1997) Epilepsy, retarded growth and onchocerciasis, in two areas of different endemicity of onchocerciasis in Burundi. Transactions Royal Society Tropical Medicine and Hygiene 91, 525-527.

Ngoumgou, E.B. \& Preux, P.M. (2008) Cerebral malaria and epilepsy. Epilepsia 49 (Suppl. 6), 19-24.

Ngoungou, E.B., Dulac, O.\& Poudiougou, B. (2006) Epilepsy as a consequence of cerebral malaria in an area in which malaria is endemic in Mali, West Africa. Epilepsia 47, 873-879.

Nicoletti, A., Bartoloni, A., Reggio, A., Bartalesi, F., Roselli, M., Sofia, V., Rosado, J., Gamboa, H., Paradisi, F., Cancrini, G., Tsang, V.C.W. \& Hall, A.J. (2002) Epilepsy, cysticercosis and toxocariasis: a population based case-control study in rural Bolivia. Neurology 58, 1256-1261

Nicoletti, A., Bartoloni, A., Sofia, V., Mantella, A., Nsengiyumva, G., Frescaline, G. \& Marie-Preux, P. (2007) Epilepsy and toxocariasis: A case-control study in Burundi. Epilepsia 48, 894-899.

Nicoletti, A., Sofia, V., Mantella, A., Vitale, G., Contrafatto, D., Sorbello, V., Biondi, R. \& Preux, P.M. (2008) Epilepsy and toxocariasis: A case-control study in Italy. Epilepsia 49, 594-599.

Nitiema, P., Carabin, H., Hounton, S., Praet, N., Cowan, L.D., Ganaba, R., Kompaore, C., Tarnagda, Z., Dorny, P., Millogo, A. \& Efecab (2012) Prevalence case-control study of epilepsy in three Burkina Faso villages. Acta Neurological of Scandinavia 126, 270-278.

Nkwi, P.N. \& Ndonko, F.T. (1989) The epileptic among the Bamilekes of Maham in the Nde division, West Province of Cameroon. Cult Medicine and Psychiatry 13, 437-448.

Nsengiyumva, G., Druet-Cabananc, M., Ramanankandrasana, B., Bouteille, B., Nsizabira, L. \& Preux, P.M. (2003) Cysticercosis as a major risk factor for epilepsy in Burundi, east Africa. Epilepsia 44, 950-955.

Nwokolo, C. (1974) Endemic paragonimiasis in Africa. Bulletin of the World health Organization 50, 569-571

Ogunniyi, A., Adeyinka, A., Gagbemi, S.O., Orere, R., Falope, Z.F. \& Oyawole, S.O. (1994) Computerized tomographic findings in adolescent and adult Nigerian epileptics. West African J ournal of Medicine 13, 128-131

Okeke, I.N., Ojo, O., Lamikanra, A. \& Kaper, J.B. (2003) Etiology of acute diarrhoea in adult in southwestern Nigeria. J ournal of Clinical Microbiology 24, 868-870.

Onadeko, M.O., Joynson, D.H. \& Payne, R.A. (1992) The prevalence of Toxoplasma infection among pregnant w omen in Ibadan, Nigeria. J ournal of Tropical Medicine and Hygiene 95, 143-145.

Ottesen, E. (1995) Immune responsiveness and the pathogenesis of human onchocerciasis. J ournal of Infectious Diseases 171, 659-671

Overgaauw, P.A. (1997) Aspect of Toxocara epidemiology: human toxocarosis. Critical Reviews of Microbiology 23, 215-231

Ovuga, E., Kipp, W., Mungherera, M. \& Kasoro, S. (1992) Epilepsy and retarded growth in a hyperendemic focus of onchorcerciasis in rural western Uganda. East African Medical J ournal 69, 554-556.

Pal, D.K., Carpio, A. \& Sander, J.W.A. (2000) Neurocysticercosis and epilepsy in developing countries. Journal of Neurology, Neurosurgery and Psychiatry 68, 137-143. 
Palmer, B.S. (2007) Meta-analysis of three case controlled studies and an ecological study into the link betw een cryptogenic epilepsy and chronic toxoplasmosis infection. Seizure 16, 657-663.

Pawloski, Z.S. (2002) Taenia: basic biology and transmission. In: Singh, G., Prabhakar, S., eds. Taenia solium cysticercosis. Wallingford, UK: CABI Publishing, 1-23.

Pion, S.D.S., Kaiser, C., Boutros-Toni, F. (2009) Epilepsy in onchorcerciasis endemic areas: systematic review and meta-analysis of population-based surveys. PLoS Neglected Tropical Diseases 3, e461

Pion, S.D. \& Boussinesq, M. (2012) Significant association between epilepsy and presence of onchocercal nodules: case-control study in Cameroon. American Journal of Tropical Medicine and Hygiene 86, 557.

Pittella, J.E. (1991) The relationship between involvement of the central nervous system in schistosomiasis mansoni and the clinical forms of the parasitosis. A review. Journal of Tropical Medicine and Hygiene 94, 15-21

Pittella, J.E.H.(1997) Neuroschistosomiasis. Brain Pathology 7, 649-682.

Potasman, I., Davidovitch, M., Tal, Y., Tal, J ., Zelnik, N. \& J affe, M. (1995) Congenital toxoplasmosis: a significant cause of neurological morbidity in Israel? Clinical Infectious Diseases 20, 259-262.

Powell, H.C., Gibbs, C.J . J r., Lorenzo, A.M., Lampert, P.W. \& Gajdusek, D.C. (1978) Toxoplasmosis of the central nervous system in the adult. Electronic microscopic observations. Acta Neuropathology (Berlin) 41, 211-216.

Preux, P.M. \& Druet-Cabanac, M. (2005) Epidemiology of epilepsy in sub-Saharan Africa. Lancet Neurology 4, 21-31

Preux, P.M., Melaku, Z. \& Druet-Cabanac, M. (1996) Cysticercosis and neurocysticercosis in Africa: Current status. Neurology and Infectious Diseases Epidemiology1, 63-68.

Quet, F., Guerchet, M., Pion, S.D.S., Ngoungou, EB., Nicoletti, A. \& Preux, P.M. (2010) A analysis of the association between cysticercosis and epilepsy. Epilepsia 51, 830-837.

Rai, D., Kerr, M.P., McManus, S., Jordanova, V., Lewis, G. \& Brugha, T.S. (2012) Epilepsy and psychiatric comorbidity: a nationally representative population-based study. Epilepsia 53,1095-1103.

Roberts, D.J ., Craig, A.G., Berendt, A.R., Pinches, R., Nash, G., Marsh, J . \& Newbold, C.I. (1992) Rapid switching to multiple antigenic and adhesive phenotypes in malaria. Nature 357, 689-692.

Ross, A.G.P., Bartley, P.B., Sleigh, A.C., Olds, R., Li, Y., Williams, G.M. \& McManus, D.P. (2002) Schistosomiasis. The New England J ournal of Medicine 346, 1212-1220.

Rwiza, H.T., Kilonzo, G.P., Haule, J., Matuja, W.B.P., Mteza, I., M bena, P., Kilima, P.M., M waluko, G., Mwang'ombola, R., Mwaijande, F., Rweyemamu, G., Matowo, A. \& J ilek-Aall, L.M. (1992) Prevalence and incidence of epilepsy in Ulanga, a rural Tanzania district: a community-based study. Epilepsia 33, 1051-1056.

Sander, J.W.A.S. \& Shorvon, S.D. (1987) Incidence and prevalence studies in epilepsy and their metho dological problems: a review. J ournal of Neurosurgery and Psychiatry 50, 829-839.

Schantz, PM. \& Glickman, L.T. (1978) Toxocaral visceral larva migrans. New England Journal of Medicine 298, 436-439.

Schoeman, C.J ., van De Vyver, A.E. \& Visvesvara, G.S. (1993) Primary amoebic meningo-encephalitis in southern Africa. J ournal of Infection 26. 21121-4.

Schuster, F. \& Visvesvara, G.S.(2004) Amebae and ciliated protozoa as causal agents of waterborne zoonotic disease. Veterinary Parasitology 126, 91-120.

Scrimgeour, E.M . \& Gajdusek, D.C. (1985) Involvement of the central nervous system in Schistosoma mansoni and S. haematobium infection. A review. Brain 108, 1023-1038.

Senanayake, N. \& Roman, G.C. (1993) Epidemiology of epilepsy in developing countries. Bulletin of the W orld Health Organization 71, 247-258. 
Siddiqui, R. \& Khan, N.A. (2012) Biology and pathogenesis of Acanthamoeba. Parasites and vectors 5:6. Sims, T.A., Hay, J \& \& Talbot, I.C. (1989) An electron microscope and immunohistochemical study of the intracellular location of Toxoplasma tissue cyst within the brains of mice with congenital toxoplasmosis. British J ournal of Experimental Pathology 70, 317-325.

Stauffer, W., Abdalla, M. \& Ravdin, J.I. (2005) Prevalence and incidence of Entamoeba histolytica infection in South Africa and Egypt. Archives of Medical Research 37, 266-269.

Stommel, E.W., Seguin, R., Thadani, V.M., Schwartman, J.D., Gilbert, K., Ryan, K.A., Tosteson, T.D. \& Kasper, L.H. (2001) Cryptogenic epilepsy: an infectious etiology? Epilepsia 42, 436-438.

Swai, E.S. \& Schoonman, L. (2009) Seroprevalence of Toxoplasma gondii infection amongst residents of Tanga district in north-east Tanzania. Tanzania J ournal of Health Research 11, 4, 205-209.

Taratuto, A.L. \& Venturiello, S.M . (1997) Trichinosis. Brain Pathology 7,663-672.

Tekle-Haimanot, R., Forsgren, L. \& Ekstedt, J. (1997) Incidence of epilepsy in rural central Ethiopia. Epilepsia 38, 541-546.

Tenter, A.M., Heckeroth, A.R. \& Weiss, L.M. (2000) Toxoplasma gondii: from animals to humans. International J ournal of Parasitology 30, 1217-1258.

Thompson, D.E., Bundy, D.A.P., Cooper, E.S. \& Schantz, P.M. (1986) Epidemiological characteristics of Toxocara canis zoonotic infection of children in a Carribean community. Bulletin of the World Health Organization 64, 283-298.

Turgut, M . (1997) Hydatid disease of the spine: a survey study from Turkey. Infection 25, 4.

Ugonabo, J.A. \& Gugnani, H.C. (1986) Nasal carriage of Naegleria fowleri and its environmental occurrence in Borno State, Nigeria. J ournal of Communicable Diseases 21, 111-113.

Uneke, C.J., Duhlinska, D.D., Njoku, M.O. \& Ngwu, B.A. (2005) Seroprevalence of acquired toxoplasmosis in HIV-infected and apparently healthy individuals in J 0S, Nigeria. Parasitologia $47,233-236$.

Wagner, R.G. \& Newton, C.R. (2009) Do helminths cause epilepsy? Parasite Immunology 31, 697 - 705.

Walker, M .D. \& Zunt, J .R. (2005) Neuroparasitic infections: Nematodes. Seminars in Neurology 25, 252261

Wassmer, S.C., Coltel, N., Combes, V. \& Grau, G.E. (2003) Pathogenesis of cerebral malaria: facts and hypotheses. Medicine Tropical (Mars), 63, 254-257.

White, N.J. (1999) Molecular mechanisms of cytoadherence in malaria. American Journal of Physiology 276, 1231- 1242.

Winkler, A.S. (2012) Neurocysticercosis in sub-Saharan Africa: a review of prevalence, clinical characteristics, diagnosis, and management. Pathology and Global Health 106, 261-274.

Winkler, A.S., Blocher, J., Auer, H., Gotwald, T., Matuja, W. \& Schmutzhard, E. (2008) Anticysticercal and antitoxocaral antibodies in people with epilepsy in rural Tanzania. Transactions of the Royal Society of Tropical Medicine and Hygiene 102, 1032-1038.

Winkler, A.S., Blocher, J., Auer, H., Gotwald, T., Matuja, W. \& Schmutzhard, E. (2009) Epilepsy and neurocysticercosis in rural Tanzania-an imaging study. Epilepsia 50, 987-993.

Winkler, A.S., Friedrich, K., Konig, R., M eindi, M., Helbok, R., Unterberger, I., Gotwald, T., Dharsee, J., Velicheti, S., Kidunda, A., J ilek-Aall, L., Matuja, W. \& Schmutzhard E. (2008) The head nodding syndrome - clinical classification and possible causes. Epilepsia 49, 2008-2015.

Winkler, A.S., Kerschbaumsteiner, K., Stelzhammer, B., Meindl, M., Kaaya, J. \& Schmutzhard, E. (2009) Prevalence, incidence and clinical characteristics of epilepsy - a community-based door-to-door study in northern Tanzania. Epilepsia 50, 2310-2313.

Winkler, A.S., Willingham, A.L., Sikasunge, C.S. \& Schmutzhard, E. (2009) Epilepsy and neurocysticercosis in sub-Saharan Africa. Wien Klin Wochenschr 121( Suppl 3): 3-12.

WHO (1995) Control of food-borne trematode infections. Report of WHO study group. Technical Report Series No. 849. Geneva 1995. 
WHO (2001a) Epilepsy: Epidemiology, Aetiology and Prognosis. WHO Factsheet

WHO (2001b) Epilepsy: Aetiology, Epidemiology and Prognosis (volume fact sheet no.165)

WHO (2011) World Malaria Report, 2011 World Health Organization, Geneva.

Wu, L., Wu, M., Tian, D., Chen, S., Liu, B., Chen, Q., Wang, J., Cai, Q., Ji, B., Wang, L., Zhang, S., Ruan, D., Zhu, X. \& Guo, Z. (2012) Clinical and imaging characteristics of cerebral schistosomiasis. Cell Biochemistry and Biophysics 62, 289-295.

Yazar, S., Arman, F., Yalcin, S., Demirtas, F., Yaman, O. \& Sahin, I. (2003) Investigation of probable relationship betw een Toxoplasma gondii and cryptogenic epilepsy. Seizure 12, 107-109.

Yemadje, L.P., Houinato, D., Boumediene, F., Ngoungou, E.B., Preux, P.M . \& Druet-Cabanac, M . (2012) Prevalence of epilepsy in the 15 years and older in Benin: a door-to-door nationwide survey. Epilepsy Research 99, 318-326.

Yin, C.Y. \& Shin, Y.Z. (2002) Investigation of inpatient cases of food-borne parasitic encephalopathy. Zhongguo J i Sheng Chong Xue Yu J i Sheng Chong Bing Za Zhi 20, 177- 179.

Zibaei, M., Zamani, Z., Esfahani, AC., Anbari, K. \& Nezar, M.R. (2011) Toxoplasma infection and epilepsy: A case-control study in Iran. Neurology in Asia 16, 4, 299-302. 